\title{
Influence of Particle Size of Titanium Dioxide on UV-ray Shielding Property ${ }^{\dagger}$
}

\author{
Masashi Sakamoto, Haruo Okuda, Hideo Futamata, \\ Akihito Sakai and Masaki Iida* \\ Ishihara Sangyo Kaisha, Ltd., Research \& Development Laboratory*
}

\begin{abstract}
The influence of particle size $(0.019-0.24 \mu \mathrm{m})$ of $\mathrm{TiO}_{2}$ on $\mathrm{UV}$-ray shielding capability was studied.

UV-ray shielding capability of $\mathrm{TiO}_{2}$ depended on the wavelength. That is, the smaller the primary particle size was, the greater its shielding capability against around $300 \mathrm{~nm}$ of $U V-B$ range was. On the contrary, for the shielding capability against around $350 \mathrm{~nm}$ of UV-A range, an optimum primary particle size was found. Furthermore, the optimum primary particle size varied, depending on dispersion strength of the particles in a paint.
\end{abstract}

\section{Introduction}

Titanium dioxide is high in refractive index, chemically stable and extremely safe to use. It is widely used as a white pigment. The titanium dioxide used for pigment is generally designed to a primary particle size of 0.2 to $0.3 \mu \mathrm{m}$ in order to maximize visible light scattering. Ultrafine particles of titanium dioxide are extremely smaller in primary particle size and present characteristic properties not found in the titanium dioxide used for pigment. They have come to be used in various fields, including sunscreen cosmetics, ultraviolet ray (UV-ray) shielding paint, ink, plastics and textiles, automotive metallic paint, and silicone rubber.

In particular, they are intensively used to cut-off UV-rays. And the relationship between the UV-ray shielding effect and particle size, in other words, the optimum particle size for maximizing the UV-ray shielding effect, has been calculated theoretically ${ }^{1-3)}$, but details have not been reported about experimental study.

The authors, using $\mathrm{TiO}_{2}$ particles of different primary particle sizes $(0.019$ to $0.24 \mu \mathrm{m})$, investigated the effects of particle size on the shielding performance of UV-ray (300 to $400 \mathrm{~nm}$ ), and searched for optimum particle size ${ }^{4)}$. Incidentally, though dispersion of $\mathrm{TiO}_{2}$ particles is more difficult when the primary particle size is smaller, the effects of dispersion strength were studied at the same time.

\footnotetext{
* 1. Ishihara-cho, Yokkaichi-city. Mie-pref., 510 Japan

† This report was originally printed in SHIKIZAI KYOKAISHI 68, 203 (1995) in Japanese, before being translated into English by KONA Editorial Committee with the permission of the editorial committee of the Japan Society of Colour Material
}

\section{Experiment}

\subsection{Samples}

$\mathrm{TiCl}_{4}$ was hydrolized by neutralization, followed by calcination, then it was ground by wet process, and treated with hydrous aluminum oxide on its surface $\left(1.5 \%\right.$ as $\mathrm{Al}_{2} \mathrm{O}_{3}$ to $\left.\mathrm{TiO}_{2}\right)$. Eight samples (A to $\mathrm{H}$ ) of rutile particles $\mathrm{TiO}_{2}$ with different primary particle sizes were prepared. The particle size was controlled mainly by changing calcination temperature.

For supplementary experiment (1), pigment type titanium dioxide CR-50 (Ishihara Sangyo Kaisha, Ltd.) and carbon black (MA-100, Mitsubishi Chemical Corp.) were used.

\subsection{Operation of experiment}

\subsubsection{Preparation of paint}

In a paint system of acrylic resin (Acrydick 47-712, Dainippon Ink \& Chemical Inc., solid content 50\%)/ melamine (Super Beckamine L-117-60, Dainippon Ink \& Chemical Inc., solid content $60 \%)=4 / 1$, paint samples were prepared by dispersing for $5,20,60$, and 180 minutes using a paint shaker, with zircon beads of $0.5 \mathrm{~mm}$ in diameter as a medium (1400 $\mathrm{g} / 100 \mathrm{~g} \mathrm{TiO} 2$ ). A pigment concentration in solid matter (PWC) was $3.3 \%$.

\subsubsection{Measurement of transmittance of paint film}

The paint was applied to a film (Fujitac Film, Fuji Photo Film Co., Ltd) in a dried film thickness of $5 \mu \mathrm{m}$ by doctor blade, and baked. Spectral transmittance (300 to $700 \mathrm{~nm}$ ) was measured using a spectrophotometer (UV-240, Shimadzu Corporation), while a clear resin was applied to a film in a same 
filin thickness to be used as blank.

\subsubsection{Electron microscopic observation}

Using a scanning electron microscope (S-800, Hitachi, Ltd.), the primary particle size of $\mathrm{TiO}_{2}$ and the dispersion state of $\mathrm{TiO}_{2}$ particles in the paint film were observed at an overall magnification of 20,000 times.

\subsubsection{Measurement of specific surface area}

The specific surface area of the $\mathrm{TiO}_{2}$ samples was measured using a specific surface area measuring apparatus (FlowSorb II 2300, Micromeritics Instru-, ment Corp.).

\subsubsection{Supplementary experiment (1)}

In the same acrylic/melamine paint system as in 2.2.1, by dispersing for 60 minutes, paints were prepared at $\mathrm{PWC}=0.33 \%$ of carbon black, and $\mathrm{PWC}=2.3 \%$ of $\mathrm{CR}-50$.

Besides, these paints were mixed at $1.5 / 8.5,3 / 7$, $5 / 5,7 / 3$, and $8.5 / 1.5$, and applied to films to a dried film thickness of $9 \mu \mathrm{m}$, and baked. Spectral transmittance and reflectivity were measured.

\section{Results and discussion}

\subsection{Calculation of particle size from specific surface area}

The specific surface area of eight samples $A$ to $H$ was measured. Results are shown in Table 1. From the measured values, the particle size was calculated by assuming $\mathrm{TiO}_{2}$ particles to be perfect spheres. The result coincided well with the primary particle size observed by electron microscope. This calculated value was regarded as the primary particle size of $\mathrm{TiO}_{2}$.

Table-1 Primary particle size (estimated from S.S.A.* value)

\begin{tabular}{|c|c|c|}
\hline Sample & $\begin{array}{c}\text { S.S.A } \\
{\left[\mathrm{m}^{2} / \mathrm{g}\right]}\end{array}$ & $\begin{array}{c}\text { Primary particle size } \\
{[\mu \mathrm{m}]}\end{array}$ \\
\hline $\mathrm{A}$ & 75.0 & 0.019 \\
\hline $\mathrm{B}$ & 49.0 & 0.029 \\
\hline $\mathrm{C}$ & 39.7 & 0.036 \\
\hline $\mathrm{D}$ & 29.8 & 0.048 \\
\hline $\mathrm{E}$ & 19.0 & 0.075 \\
\hline $\mathrm{F}$ & 14.9 & 0.096 \\
\hline $\mathrm{G}$ & 8.9 & 0.16 \\
\hline $\mathrm{H}$ & 6.0 & 0.24 \\
\hline
\end{tabular}

${ }^{*}$ S.S.A, specific surface area
3.2 UV-ray shielding capability and particle size

Microscopic observations of the dispersion state of sample paint are shown in Figure 1. Extreme agglomeration was noted in paint samples of short dispersion time, and in spite of using sample $C$ where primary particle size was $0.036 \mu \mathrm{m}$, many agglomerated particles of even 0.2 to $0.3 \mu \mathrm{m}$ were observed. The longer dispersion time, the more dispersion advanced, and agglomerated particles became smaller and fewer. But even at a dispersion time of 180 minutes, particles were not dispersed completely to the primary particle size, and this tendency was the same in all samples.

Figure 2 shows changes in transmittance of ultraviolet rays in relation to the primary particle size under strong dispersion. In the wavelength range of 300 to $400 \mathrm{~nm}$, the shorter the wavelength of ultraviolet ray, the lower the transmittance for titanium dioxide of any particle size. The transmittance of ultraviolet rays of $300 \mathrm{~nm}$ tends to decline as the primary particle size becomes smaller, and in ultraviolet rays of 325 to $400 \mathrm{~nm}$, minimum values of transmittance were noted. The optimum particle size, from the viewpoint of UV-ray shielding, was
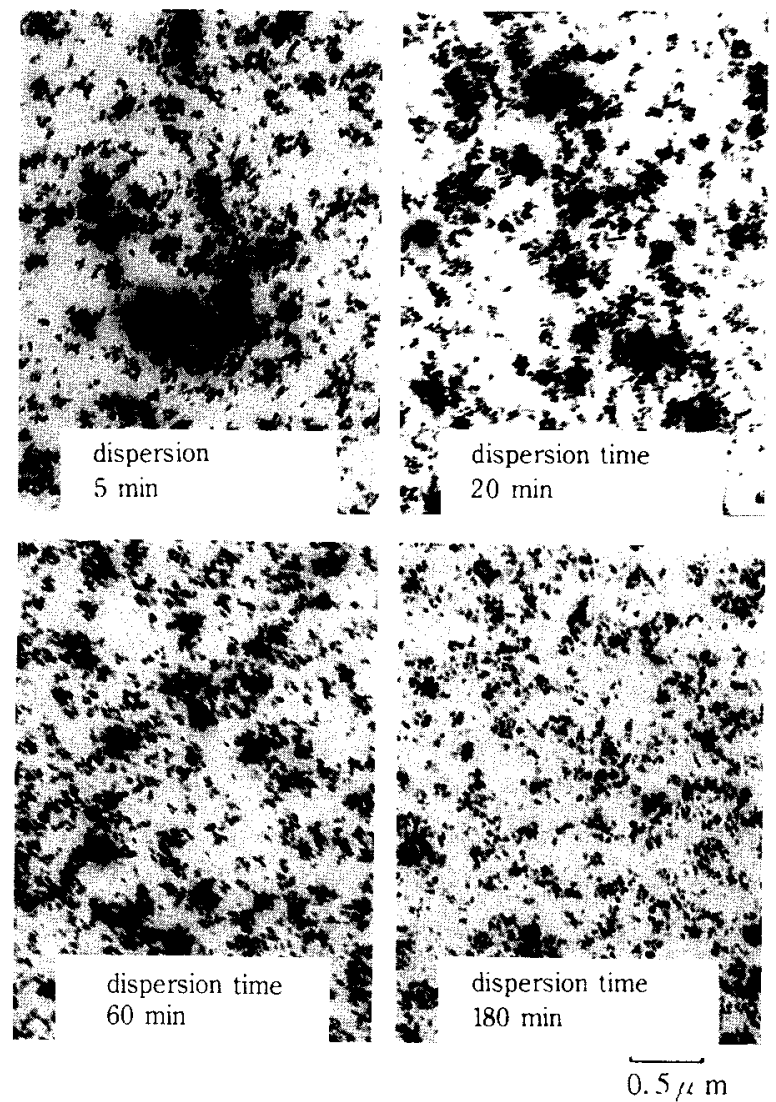

Fig. 1 SEM photographs of sample C. 
found to depend on wavelength. Figure 3 shows calculation results by $P$. Stamatakis ${ }^{1)}$. Results in Figure 2 seem to be very close to these calculation results. Incidentally, Figure $\mathbf{2}$ and Figure $\mathbf{3}$ are identical in terms of pigment concentration $\times$ film thickness.

Figure 4 gives results of reflectance measurements on a black substrate. As a result, reflectance at 300 and $325 \mathrm{~nm}$ was considerably low, and there was no maximum value for particle size. But in ultraviolet rays of $350 \mathrm{~nm}, 375 \mathrm{~nm}$, and $400 \mathrm{~nm}$, maximum values were observed. Reflectance was

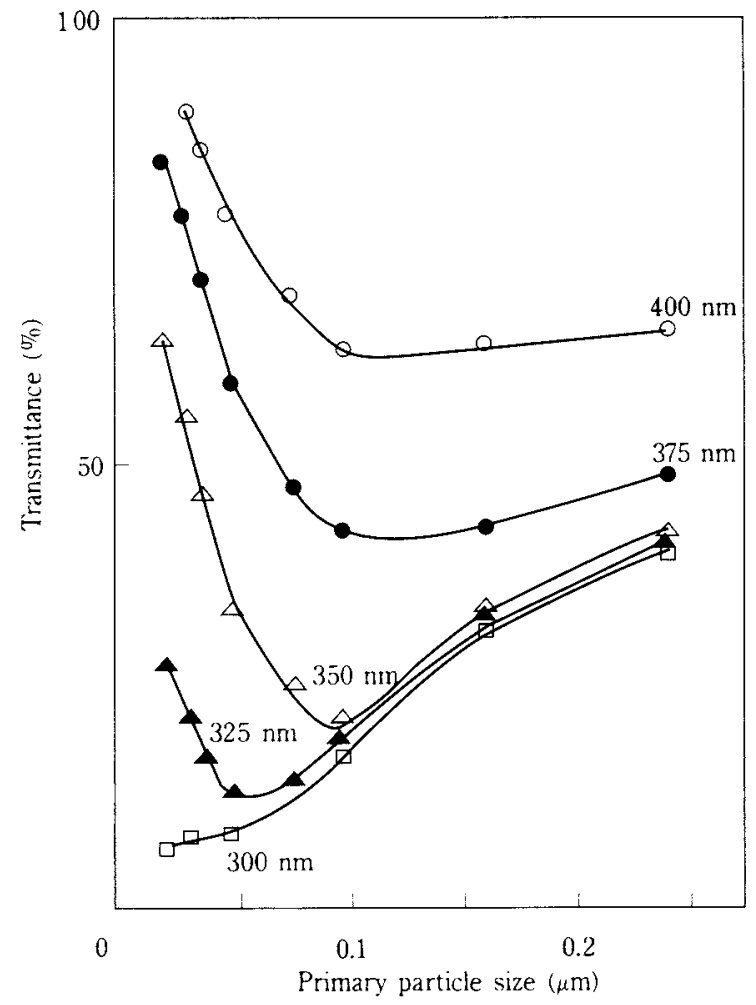

Fig. 2 Relation between transmittance and primary particle size.

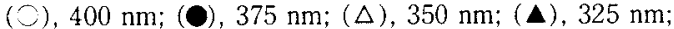
(こ), $300 \mathrm{~nm}$. Dispersion time, $180 \mathrm{~min}$.

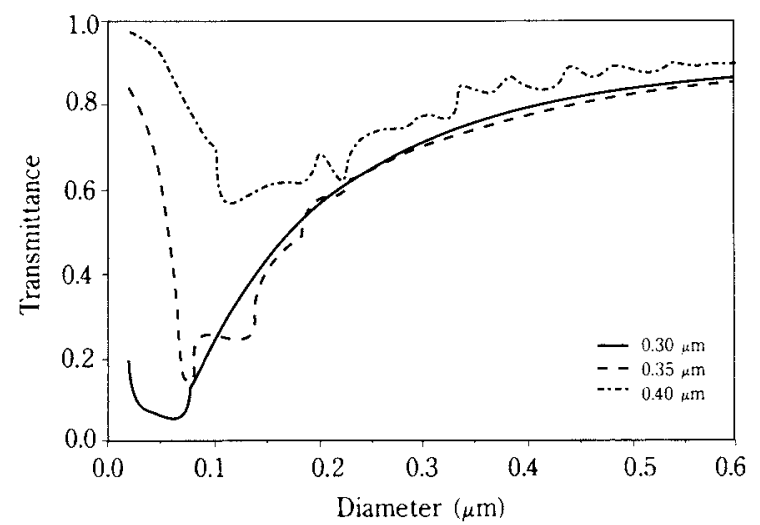

Fig. 3 Transmittance of a film containing spherical titanium dioxide particles as a function of particle size ${ }^{1)}$.

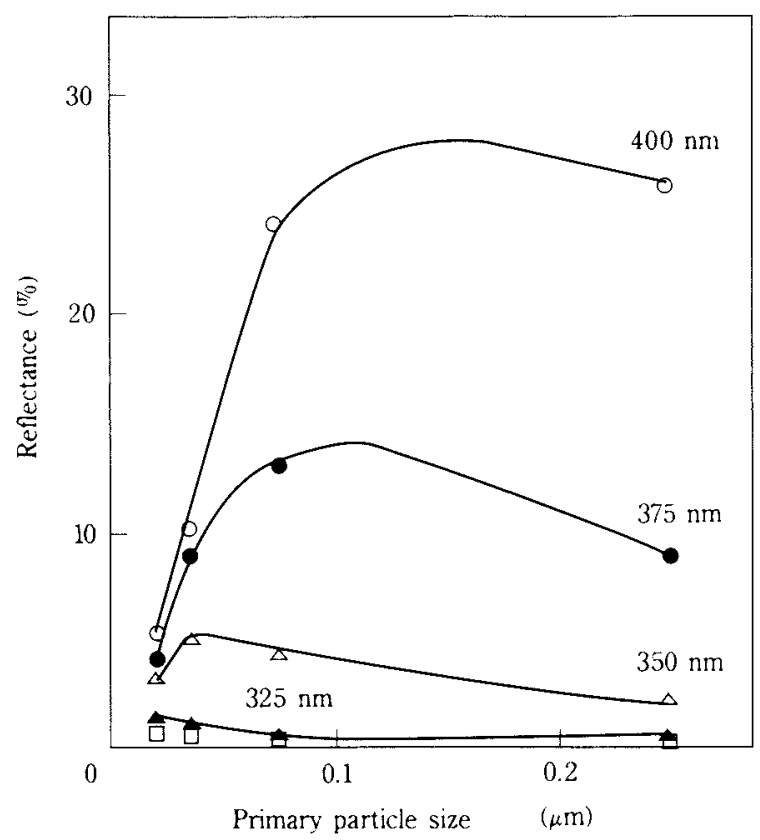

Fig. 4 Relation between reflectance and primary particle size.

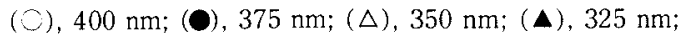
(二), $300 \mathrm{~nm}$. Dispersion time, $180 \mathrm{~min}$.

greater in longer wavelength of ultraviolet rays. Considering this together with the results in Figure 2, especially at $400 \mathrm{~nm}$, UV-ray shielding capability seems to depend mostly on scattering capability.

Reflectance measured in this method was influenced by absorption and did not always represent true scattering capability. Roughly speaking, if we assume the reflected light to be scattered at an average point of a paint film thickness $\times 1 / 2$, corrected reflectance can be determined with the following formula, subtracting the influence of absorption.

Reflectance $($ corrected value $)=$ Measured reflectance / Transmittance $\times 100$

This equation is plotted in Figure 5.

By comparison of Figure $\mathbf{5}$ and Figure 2, the contribution of absorption and scattering to the UV-ray shielding effect of titanium dioxide may be estimated as follows.

$400 \mathrm{~nm}$ : Shielding capability is mostly due to scattering.

$375 \mathrm{~nm}$ : $\quad$ Effects of scattering and absorption are nearly balanced.

$350 \mathrm{~nm}$ : $\quad$ Effect of absorption is greater, but scattering cannot be ignored.

325 to $300 \mathrm{~nm}$ : Mostly due to absorption. 


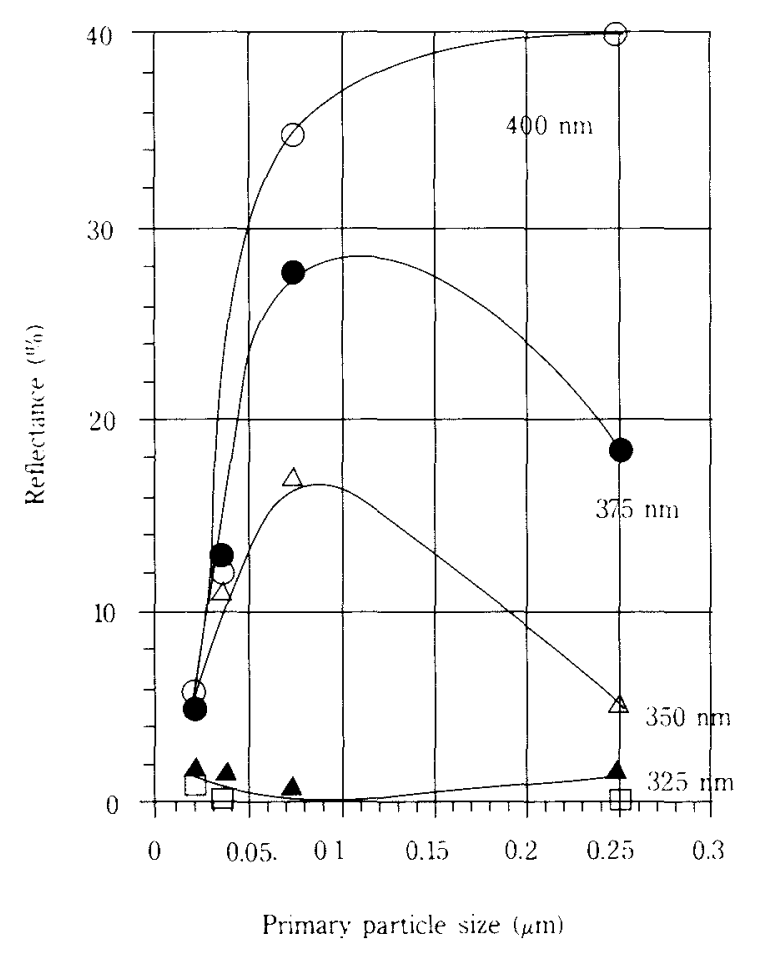

Fig. 5 Relation between reflectance (corrected value) and primary particle size. (O), $400 \mathrm{~nm} ;(\circlearrowleft), 375 \mathrm{~nm} ;(\triangle), 350 \mathrm{~nm}$; (৫), $325 \mathrm{~nm}$; (匚), $300 \mathrm{~nm}$. Dispersion time, $180 \mathrm{~min}$.

To prove these results further, relationship between UV-ray absorption and particle size was simulated using a following model. The conditions of the present evaluation are $\mathrm{PWC}=3.3 \%$ and a dry film thickness of $5 \mu \mathrm{m}$. Hence, the titanium dioxide weight $W$ existing in coated film $1\left[\mathrm{~cm}^{2}\right] \times 5 \times 10^{-4}[\mathrm{~cm}]$ (assuming the specific gravity of the coated film to be 1 ) is obtained as follows.

$$
W=5 \times 10^{-4} \times 3.3 \times 10^{-2}[\mathrm{~g}]
$$

Also, assuming there are $\mathrm{n}$ spherical particles with mean particle radius $r[\mathrm{~cm}]$, the projected area $S t$ $\left[\mathrm{cm}^{2}\right]$ is as follows.

$$
S t=\pi r^{2} \cdot n
$$

And, assuming the specific gravity of titanium dioxide to be $\varrho, W$ may be expressed as follows.

$$
W=4 \pi r^{3} \cdot \varrho \cdot n / 3
$$

From formulas (1), (2) and (3), St is expressed in the following relation in terms of $r$, assuming $e$ $=4.2$.

$$
S t=2.9 \times 10^{-6} / r
$$

From this formula, supposing the projected sections of each particle do not overlap each other (actually overlapping in part, though), it is required that $S t \geq 1$ in order to cover $1 \mathrm{~cm}^{2}$ completely. It is thus known from formula (4) that all of $1 \mathrm{~cm}^{2}$ cannot be covered unless the particle size is $0.0292 \times 2=0.058[\mu \mathrm{m}]$ or less.

To observe changes in transmittance when the particle size was larger than $0.058 \mu \mathrm{m}$, calculations were attempted by approximating the spherical particles to a rectangular shaped object having the same projected sectional area and volume as shown in Figure 6.

Seeing the coated film surface from the vertical direction as shown in Figure 7, the area occupied by titanium dioxide is supposed to be $S_{1}$, and the area free from titanium dioxide to be $S_{2}$. Hence, $P S$ is defined as follows (assuming whole area of coated film to be $\left.S_{\text {all }}=S_{1}+S_{2}\right)$.

$$
P s=S_{1} /\left(S_{1}+S_{2}\right)=S_{1} / S_{\text {all }}
$$

Assuming the volume of total titanium dioxide contained in the coat film to be $V$, the transmittance at $S_{1}=S_{\text {all }}$ to be $T_{0}$, and the thickness of titanium dioxide at this time to be $L_{\text {all }}\left(V / S_{\text {all }}=L_{\text {all }}\right)$, it follows that;

$$
\ln T_{0}=-\beta \cdot L_{\text {all }}
$$

Wherein, $\beta$ denotes the absorption coefficient of titanium dioxide.
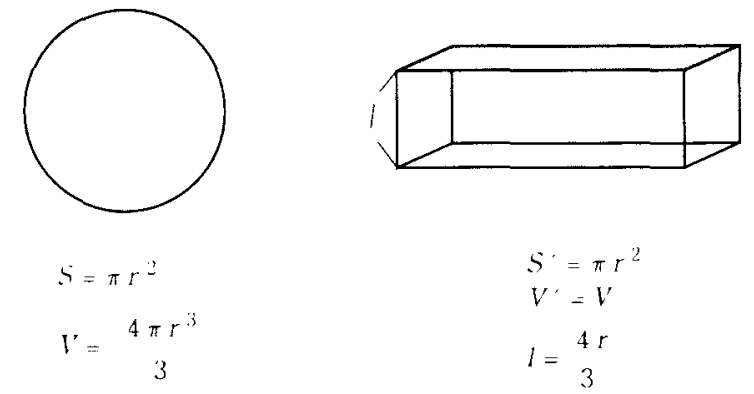

Fig. 6 Schematic model of particle shape conversion

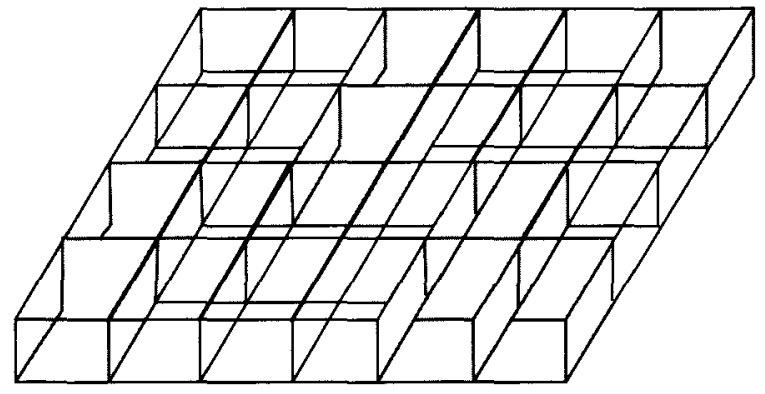

Fig. 7 Occupation model of the film with $\mathrm{TiO}_{2}$ particle. ( $), S_{1}$, the area occupied with $\mathrm{TiO}_{2}$ particle; $(=), S_{2}$, the vacant area. 
If $0 S_{2}<S_{a l l}$, assuming the transmittance in $S_{1}$ and $S_{2}$ parts to be $T_{1}$ and $T_{2}$, respectively, mean transmittance $T$ in $S_{a l l}$ is;

$$
T=\left(S_{1} T_{1}+S_{2} T_{2}\right) / S_{\text {all }}
$$

Herein, the absorption and reflection by the base film and resin are ignored, and it follows that $T_{2}=1$. From formulas (5) and (7), we obtain the following.

$$
T=P s \cdot T_{1}+1-P s
$$

Similarly, $T_{1}$ is expressed in formula (9).

$$
\ln T_{1}=-\beta \cdot\left(V / S_{1}\right)
$$

From formulas (5), (6), and (9), the following formula is obtained.

$$
\begin{gathered}
\ln T_{1}=\left(\operatorname{In} T_{0}\right) / P_{S} \\
T_{1}=T_{0}{ }^{(1 / P s)}
\end{gathered}
$$

Then, from formulas (8) and (10), the following equation is deduced.

$$
T=P_{s} \cdot T_{0}^{(1 / P s)}+1-P s
$$

Plotting for $P_{S}=0$ to 1 is shown in Figure 8

As seen in this figure, when transmittance $T_{0}$ is low at $P s=1$, that is, when the absorption capability is high, the drop in absorption that occurs when the particle size is increased is very significant, i.e., transmittance is raised notably. In contrast, when transmittance $T_{0}$ is high at $P_{S}=1$, even if the

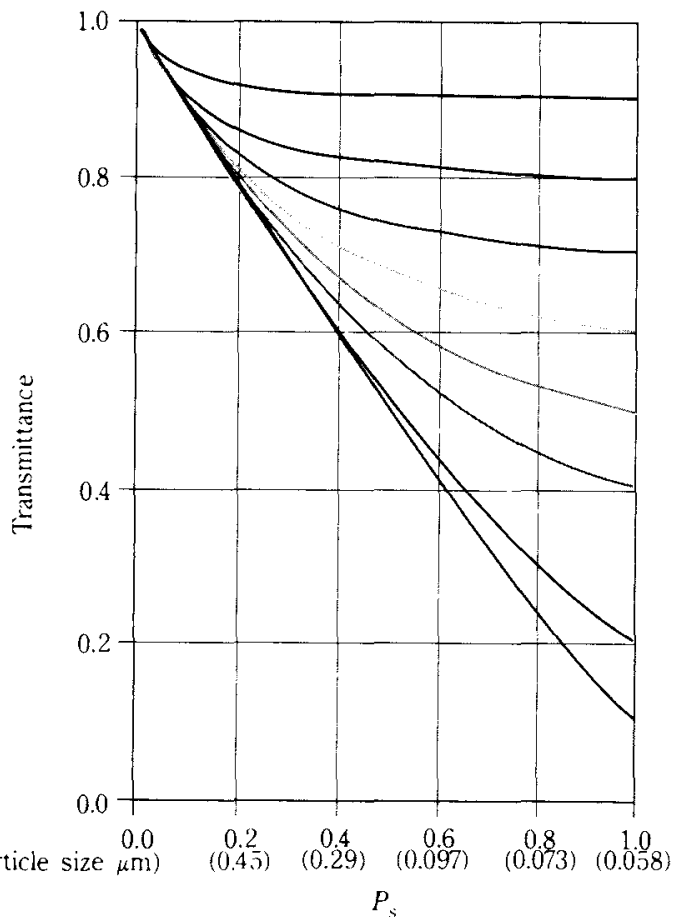

Fig. 8 Relation between transmittance and Ps. PWC, 3.3\%; dry-film thickness, $5 \mu \mathrm{m}$; calculation model. particle size is increased somewhat, absorption capability is hardly lowered and transmittance rarely changes.

This result seems compatible with the following phenomena: At around $400 \mathrm{~nm}$, where the absorption capability is low, absorption capability is not raised much, while scattering is lowered, if the particle size becomes smaller. Thus, the maximum UV-ray shielding capability is found with a relatively large particle size. On the other hand, at around $300 \mathrm{~nm}$, where the absorption capability is high, absorption capability rises significantly as particle size becomes smaller, and decrease of scattering capability can be ignored. Thus, UV-ray shielding capability is raised when the particle size becomes smaller.

Effects of dispersion time are shown in Figures 9 to 11 . Figure 9 shows relation between transmittance at $300 \mathrm{~nm}$ and dispersion time for samples differing in primary particle size. In all cases, transmittance is lowered with an increase of dispersion time. In other words, the smaller the particle size, the higher the shielding capability becomes ${ }^{6}$ ).

Figure 10 shows results at a wavelength of $400 \mathrm{~nm}$, which are very similar to the results obtained with a visible light of $550 \mathrm{~nm}$ (Figure 12).

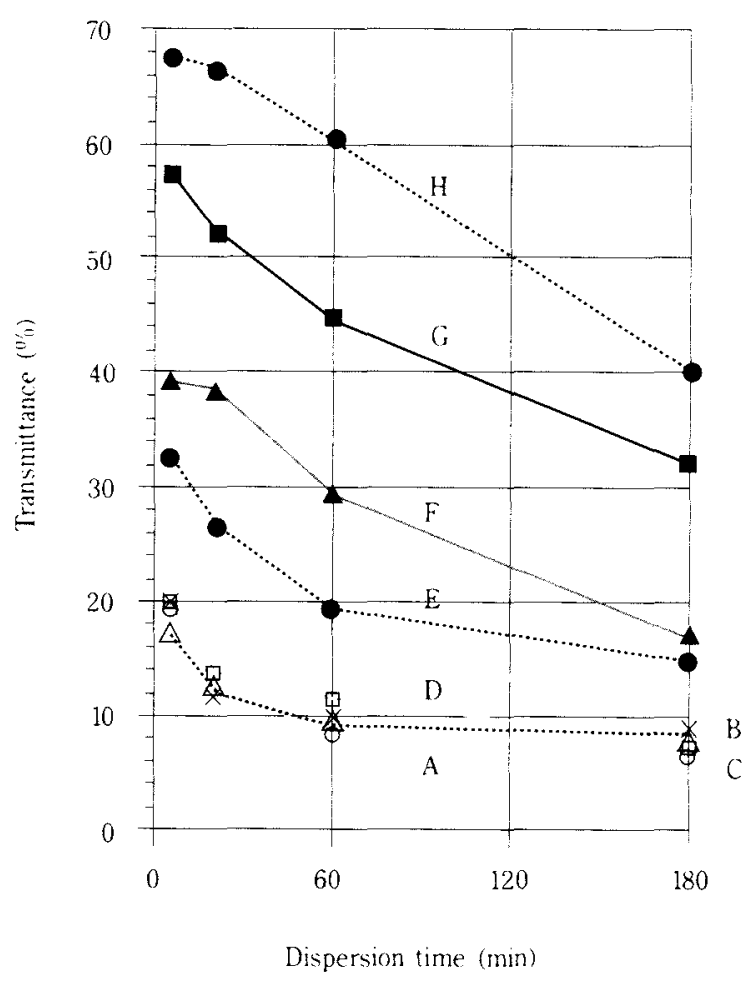

Fig. 9 Relation between transmittance (at $300 \mathrm{~nm}$ ) and dispersion time. (C), Sample A $0.019 \mu \mathrm{m}$; $\triangle$ ), Sample B $0.029 \mu \mathrm{m}$; (匹), Sample C $0.036 \mu \mathrm{m}$; (×), Sample D $0.048 \mu \mathrm{m}$; (

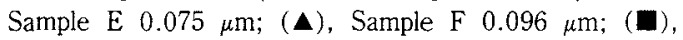
Sample G $0.16 \mu \mathrm{m} ; \bullet$ ), Sample H $0.24 \mu \mathrm{m}$. 


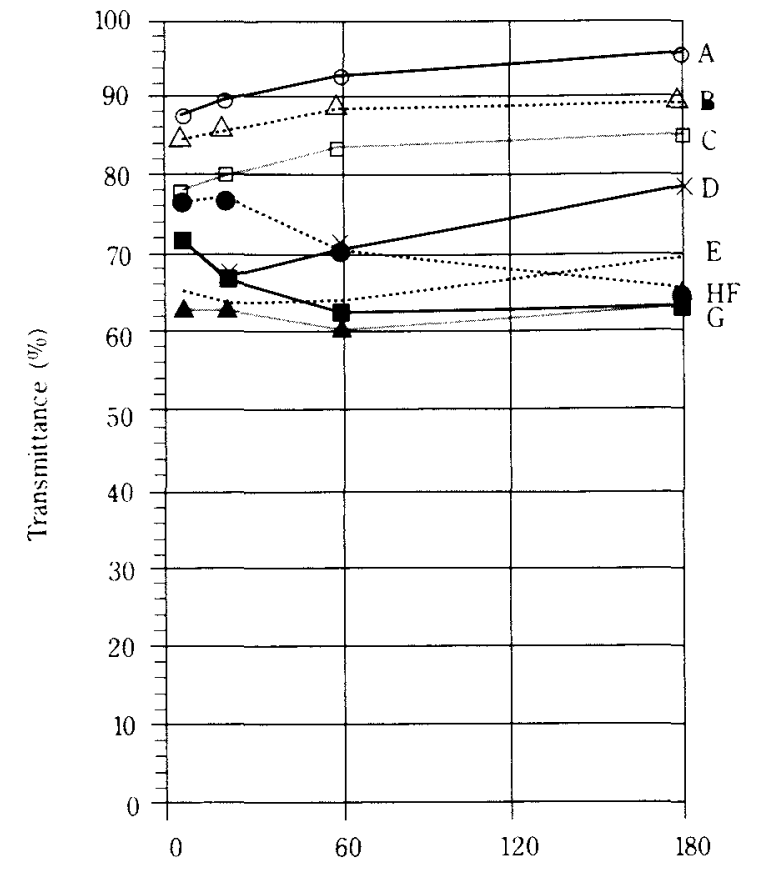

Fig. 10 Relation between transmittance (at $400 \mathrm{~nm}$ ) and dispersion time. (O), Sample A $0.019 \mu \mathrm{m} ;(\Delta)$, Sample B $0.029 \mu \mathrm{m}$; $(\square)$, Sample C $0.036 \mu \mathrm{m}$; ( × ), Sample D $0.048 \mu \mathrm{m}$; ( $(\mathbf{})$, Sample E $0.075 \mu \mathrm{m} ;(\boldsymbol{\Delta})$, Sample F $0.096 \mu \mathrm{m}$; (ם), Sample G $0.16 \mu \mathrm{m}$; $\bullet$ ), Sample H $0.24 \mu \mathrm{m}$.

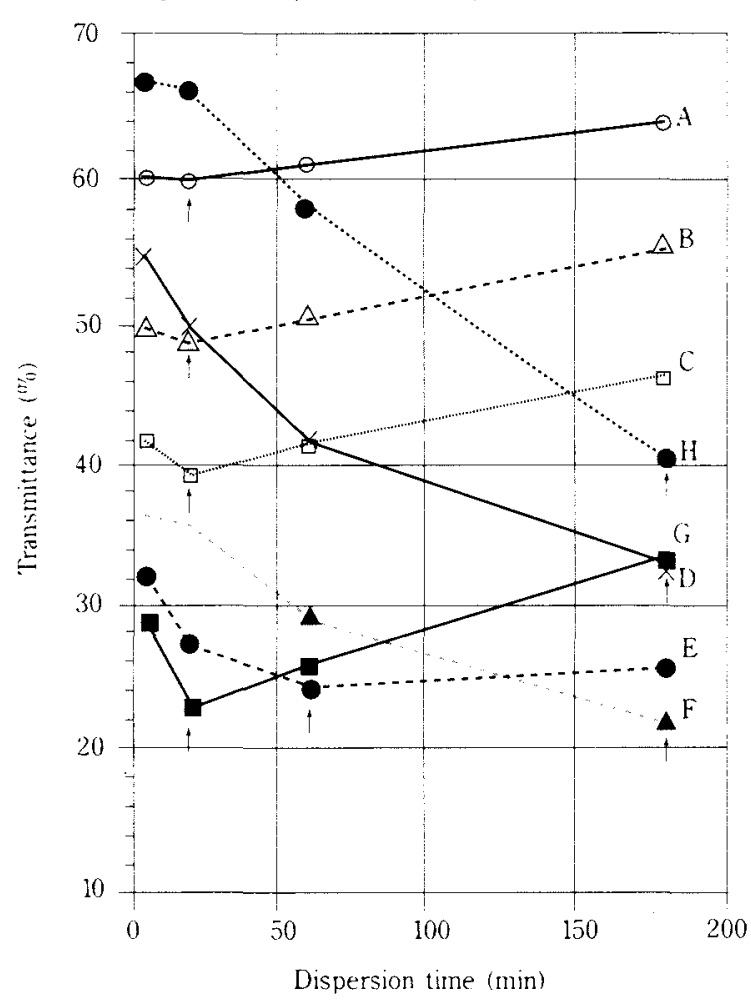

Fig. 11 Relation between transmittance (at $350 \mathrm{~nm}$ ) and dispersion time. (O), Sample A $0.019 \mu \mathrm{m} ;(\triangle)$, Sample B $0.029 \mu \mathrm{m}$;

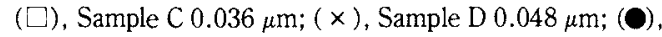
Sample E $0.075 \mu \mathrm{m} ;(\mathbf{\Lambda})$, Sample F $0.096 \mu \mathrm{m}$; ( $)$, Sample G $0.16 \mu \mathrm{m}$; $\diamond)$, Sample H $0.24 \mu \mathrm{m}$.

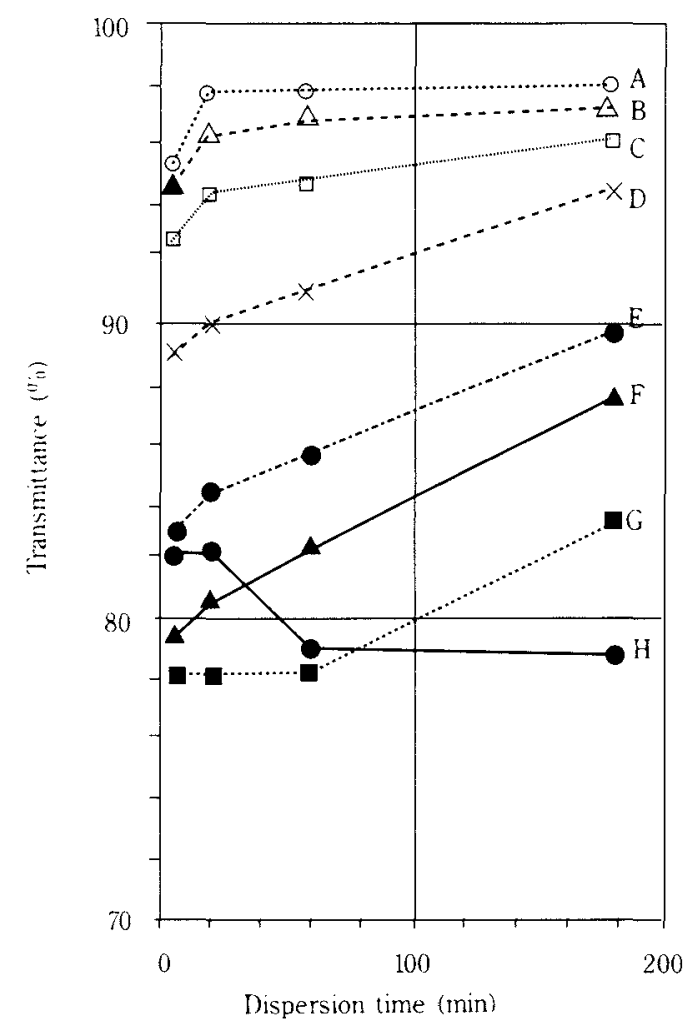

Fig. 12 Relation between transmittance (at $550 \mathrm{~nm}$ ) and dispersion time. (O), Sample A $0.019 \mu \mathrm{m} ;(\Delta)$, Sample B $0.029 \mu \mathrm{m}$; $(\square)$, Sample C $0.036 \mu \mathrm{m} ;(\times)$, Sample D $0.048 \mu \mathrm{m} ;(\bullet)$, Sample E $0.075 \mu \mathrm{m}$; ( $\mathbf{\Delta})$, Sample F $0.096 \mu \mathrm{m}$; (ם), Sample G $0.16 \mu \mathrm{m}$; $(\bullet)$, Sample H $0.24 \mu \mathrm{m}$.

The shielding capability for visible light of $550 \mathrm{~nm}$ is mostly due to scattering. Hence, at a wavelength of $400 \mathrm{~nm}$ as well, the majority of shielding capability may be considered due to scattering.

Figure 11 shows results at a wavelength of $350 \mathrm{~nm}$, in which transmittance is lowered when dispersion time is extended for larger particles of primary particle size of $0.096 \mu \mathrm{m}$ or more. On the other hand, in samples of a primary particle size of $0.075 \mu \mathrm{m}$ or less, dispersion time required to minimize transmittance was found. Hence, to shield ultraviolet rays of a wavelength of $350 \mathrm{~nm}$, there seems to be an optimum particle size of titanium dioxide in a range of 0.075 to $0.096 \mu \mathrm{m}$.

From the present study, the UV-ray shielding capability of titanium dioxide is confirmed due to the combined effect of scattering and absorption capabilities. Absorption is dominant in ultraviolet rays of short wavelength, while scattering is superior in ultraviolet rays of long wavelength.

Finally, the combined effect of scattering and absorption was studied, the results of which are shown in Figure 13. At a wavelength of $550 \mathrm{~nm}$, pigment class $\mathrm{TiO}_{2}$ mainly showing scattering charac- 


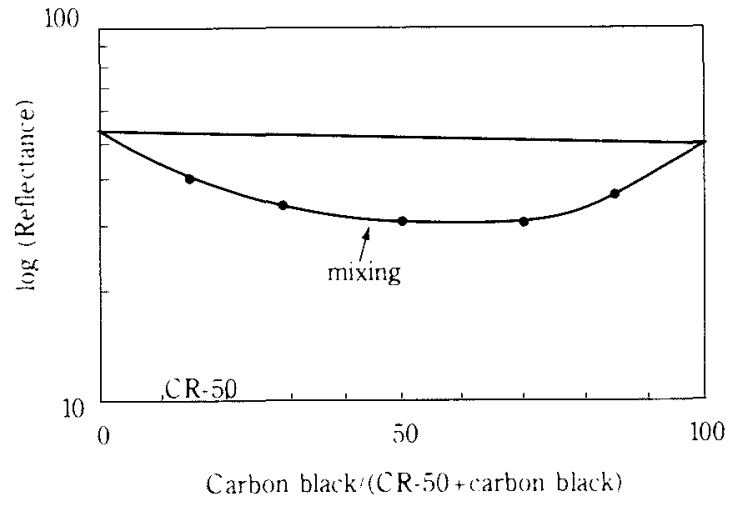

Carbon black

Fig. 13 Effect of mixing with CR-50 and carbon black on reflectance at $550 \mathrm{~nm}$.

teristics and carbon black mainly showing absorption characteristics were mixed at various blending ratios. The changes in transmittance of the coated film are shown. In either material alone, transmittance is about $50 \%$, but when mixed, evidently, trans- mittance shows less than $50 \%$. In fact, when mixed at $5 / 5$, transmittance was $30 \%$ and a significant shielding capability was exhibited.

Ultrafine particles of titanium dioxide have the ability to both absorb and scatter ultraviolet rays, and it is estimated that an excellent shielding capability was demonstrated by their combined effects.

\section{References}

1) P. Stamatakis, B.R. Palmer, G.C. Salzman, C.F. Bohren and T.B. Allen: J. Coat. Technol., 62 [10], 95 (1990)

2) C.F. Bohren: Am. J. Phys., 55 [6], 524 (1987)

3) P.S. Mudgett and L.W. Richards: Appl. Opt., 10 [7], 1485 (1971)

4) M. Sakamoto, H. Okuda, H. Futamata \& A. Sakai, Collected papers of research meeting of Japan Association of Coloring Matter, 2B-33 (1993)

5) K. Kubo, Powder, p. 177, Maruzen (1985)

6) K. Shibata, Spectrum Measurement and Spectrophotometer, pp. 21-23, Kodansha Scientific (1974)

\section{Author's short biography}

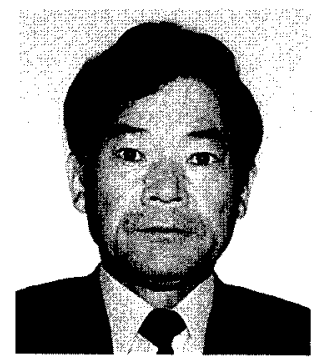

\section{Masashi Sakamoto}

Graduated, Department of Chemistry, Faculty of Science, Okayama University in 1964. Began to Work for ISHIHARASANGYO KAISHA from 1964. Inagulated a Director in 1996. Now, Deputy General Manager of Technical Research Institute. 